The only reference to British psychology is a chapter on Francis Galton and the psychology of individual differences. This once again covers familiar ground and it is a pity that a recent biography by D.W. Forrest, altogether more digestible than Pearson's monumental three volumes, fails to find useful in stressing Galton's fascinating studies of visual imagery and wordassociation, which have been relatively neglected in recent years, and he deserves credit for not getting too embroiled in the nature-nurture controversy, so productive of emotion though hardly of wisdom in contemporary psychological discussion.

The last two chapters bring us closer to the modern scene. The penultimate chapter gives an account of Pavlov's work followed by a short outline of the history of behaviourism. Although the account of J. B. Watson's life and work is not without historical interest, it fails to bring out fully how little behaviourism, in its early days at least, owed to Pavlov (it was more influenced by his rival Becterev); nor how greatly Pavlov himself detested behaviourism, which he regarded as little better than the mentalistic psychology it mention. Fancher's short account is

replaced. The importance of Lashley as a co-founder of behaviourism is insufficiently stressed. The final chapter contrasts Jean Piaget with B. F. Skinner, both described as modern pioneers. Only the future will show.

Although much of this book has been compiled from secondary sources and makes no advance on the widely accepted version of the history of experimental psychology which we owe to the late $E$. G. Boring, this book can be recommended for its thoughtful and wellwritten account of some important threads in its more recent phases of development. It is only perhaps in the sections dealing with German psychology that the author fails in some measure to catch the spirit of the age, due to the probability that he is unable to read German. Although it may be true that English is now the accepted language of European science, the historian of science would do well to acquire at all events, a reading knowledge of the mother tongue of European scientists.

$O$. L. Zangwill is Professor of Experimental Psychology at the University of Cambridge, UK.

\section{Free radical chemistry}

Radicals. By D.C. Nonhebel, J.M. Tedder and J.C. Walton. Pp. 200. (Cambridge University Press: Cambridge, 1979.) Hardback £14; paperback £5.50.

To cover adequately the many important aspects of free radical chemistry in approximately 200 pages, even at the undergraduate level, is an impossible task. This book makes an excellent attempt at the impossible.

The book is aimed at honours and postgraduate chemists but should also be useful to chemists at all levels in need of background information on radical chemistry. The coverage is wide-ranging although the depth of treatment is variable. Almost no original references are quoted but there is an extensive list of books and reviews for each chapter collected at the end of the book.

Not unexpectedly, in view of the authors' research interests, the chapters entitled "Radical transfer reactions" (18 pages), and "Radical addition reactions" ( 22 pages) are particularly well done and are a firstclass source of facts and current concepts of radical mechanisms. The chapter on "Radicals in biological systems" (15 pages) is also admirable and timely, as this is a growth area in free radical chemistry. Indeed, I would have preferred if this chapter had been somewhat longer, perhaps at the expense of part of that on
"Radical polymerisation"' (13 pages). The chapter devoted to "Stereochemistry of free radicals" ( 9 pages) is also most welcome, as this subject usually receives little attention in textbooks at this level. Awareness of the shape and preferred conformations of radicals is essential if a proper understanding of radical reactions is to be achieved.

Oxidation and reduction in free radical chemistry is a notoriously difficult subject to cover because the terms themselves seem to mean different things to different chemists and the subject matter does not lend itself easily to uniform treatment. Because of this the 15-page chapter on this subject seemed rather short and I would have preferred to have seen a fuller account given.

The book also gives brief introductions to the use of electron spin resonance spectroscopy and CIDNP, and there are chapters on combustion, radical reactions, homolytic aromatic substitution, radical rearrangements, and radical displacement reactions. All of these are sound, although perhaps not quite as good as some of the chapters mentioned earlier.

In summary, I can fully recommend this book as a compact account of present-day free radical chemistry. My criticisms of it are minor and are essentially restricted to the space allocation given to the various subjects.

A.R. Forrester

A.R. Forrester is Senior Lecturer in Chemistry at the University of Aberdeen, UK.

\section{Reptilian}

\section{ear}

The Reptile Ear: Its Structure and Function. By Ernest Glen Wever. Pp. 1024. (Princeton University Press: Princeton, New Jersey, and Guildford, UK, 1979.) $\$ 50 ; £ 31.30$.

The Reptile Ear is a monumental work of outstanding importance, representing more than 25 years of effort by a distinguished scientist. Much of the work described in this book has not been published before.

Detailed studies of the external, middle, and internal ears of 247 species of reptiles were investigated, including 186 species of lizards belonging to 16 families; 19 species of snakes; 14 species of amphisbaenians; 24 species of turtles; 3 species of crocodilians; and the single existing species of rhynchocephalians.

Wever's investigations were both anatomical and physiological, and this greatly enhances the significance of this work. The anatomical studies were carried out by means of serial celloidin sections. It is remarkable that Wever achieved such excellent and accurate detail by a light microscopic method, as his structural interpretations have been corroborated by scanning electron microscopic studies made by other workers.

Wever presents all his anatomical findings by drawings of excellent quality. It would have been helpful to others, however, to have at least some sections represented by photomicrographs.

A great deal of quantitative structural information is presented, such as papilla basilaris lengths, widths, hair cell numbers, basilar membrane width, numbers of rows of hair cells, and so on. Of particular interest is Wever's descriptions and classifications of various types of tectorial membranes.

Wever's evaluation of the functional capacity of these many ears is by use of the cochlear potential method. In many cases, Wever demonstrates increased functional capacity to be related to structural complexities. Such, however, is not always the case.

A great deal of attention is also directed to discussions of the mechanics of hair cell excitation, a problem of salient importance and interest at the moment. The concluding chapter on the biological and evolutionary significance of the reptilian ear is somewhat brief and perhaps properly conservative. Throughout the text, however, Wever indicates structure in relation to phylogeny and evolution. That the reptiles "experiment" widely with many ear components has been well demonstrated and is one of the reasons for the great interest in the reptilian ear. 